\title{
Seleção de progênies de eucalipto pelo índice Z por MQM e Blup
}

\author{
Cristiane Aparecida Fioravante Reis ${ }^{(1)}$, Flávia Maria Avelar Gonçalves ${ }^{(2)}$, \\ Magno Antonio Patto Ramalho( ${ }^{(2)}$ e Antônio Marcos Rosado(3)
}

\begin{abstract}
(1)Embrapa Florestas, Estrada da Ribeira, Km 111, CEP 83411-000 Colombo, PR. E-mail: Cristiane.Reis@embrapa.br (2)Universidade Federal de Lavras, Departamento de Biologia, Caixa Postal 37, CEP 37200-000 Lavras, MG. E-mail: avelar@dbi.ufla.br, magnoapr@dbi.ufla.br ${ }^{(3)}$ Celulose Nipo-Brasileira S.A., Rodovia BR 381, Km 172, CEP 35196-000 Belo Oriente, MG. E-mail: antonio.rosado@cenibra.com.br
\end{abstract}

Resumo - O objetivo deste trabalho foi avaliar a eficiência do índice Z (índice somatório das variáveis padronizadas) na seleção de progênies de irmãos completos entre Eucalyptus grandis e Eucalyptus urophylla via método dos quadrados mínimos (MQM) e da melhor predição linear não viesada (Blup). Os experimentos foram realizados em dois tipos de solo e de ambiente, em blocos ao acaso com cinco repetições, oito plantas por parcela e espaçamento de $3 \times 2 \mathrm{~m}$. Aos três anos de idade, as plantas foram avaliadas quanto ao incremento médio anual de madeira, à densidade básica, ao rendimento de celulose e ao álcali efetivo. Para a comparação da eficiência da seleção das melhores progênies, pelos procedimentos MQM e Blup, foi obtido o índice Z para cada indivíduo. Posteriormente, foram obtidas as médias preditas das progênies para o índice $Z$, ranqueadas em sentido favorável ao melhoramento. $O$ índice clássico também foi utilizado. A coincidência entre as melhores progênies selecionadas pelos índices clássico e $Z$ foi boa. No entanto, o índice $Z$ permite visualização gráfica, o que possibilita verificar em quais caracteres uma determinada progênie apresenta alguma deficiência. Não há diferença entre as melhores progênies selecionadas pelo índice $Z$ via MQM e Blup.

Termos para indexação: Eucalyptus, correlação genética, melhoramento florestal, índices de seleção.

\section{Selection of eucalyptus progenies by Z index through LSM and Blup}

\begin{abstract}
The objective of this work was to evaluate the efficiency of the $\mathrm{Z}$ index (sum of standardized variables index), in the selection of full-sib progenies between Eucalyptus grandis and Eucalyptus urophylla via least square method (LSM) and best linear unbiased prediction (Blup) procedures. The experiments were carried out in two soil types and environments, in a randomized complete block design, with five replicates, eight plants per plot and $3 \times 2 \mathrm{~m}$ spacing. Wood average annual increment, basic density, screened pulp yield, and effective alkali were evaluated for three-year-old plants. The $\mathrm{Z}$ index was obtained for each plant in order to compare the efficiency of selection for the best progenies by LSM and Blup procedures. Subsequently, the predicted averages to $Z$ index were obtained and ranked. For comparison, the classic index was used. The coincidence among the best progenies selected by classical and $\mathrm{Z}$ index was good. However, the $\mathrm{Z}$ index allows a graphic display that enables to check in which characters the progenie has a disability. There is no difference between the best progenies selected by the Z index via LSM and Blup.
\end{abstract}

Index terms: Eucalyptus, genetic correlation, forest breeding, selection index.

\section{Introdução}

O aumento da produtividade florestal e a melhoria das propriedades tecnológicas da madeira têm sido as principais demandas dos programas de melhoramento de Eucalyptus para a produção de celulose de fibra curta no Brasil. Com efeito, tanto produtividade quanto a qualidade da madeira contribuem para a redução de custos operacionais, para a melhoria da performance da matéria-prima no processo industrial, bem como para a adequação dessa matéria-prima à fabricação de produtos de alta qualidade para diferentes segmentos de mercado (Fonseca et al., 2010b).
Como vários caracteres de crescimento e de qualidade da madeira devem ser considerados na seleção do melhor indivíduo ou progênie, o uso de índices de seleção é uma boa opção para avaliá-los (Bernardo, 2002). Índices de seleção, como o clássico (Smith, 1936; Hazel, 1943), o índice de ganhos desejados (Pesek \& Baker, 1969), base (Willians, 1962), o índice livre de pesos e parâmetros (Elston, 1963) e o da soma de postos ou "ranks" (Mulamba \& Mock, 1978) têm sido tradicionalmente utilizados no melhoramento genético florestal (Paula et al., 2002; Martins et al., 2003, 2006). Na escolha do melhor índice de seleção, deve-se levar em consideração a facilidade de análise 
e de interpretação. Nesse sentido, o índice de seleção com base no somatório das variáveis padronizadas índice $Z$-, proposto recentemente para o melhoramento genético de culturas anuais, é uma boa alternativa em relação aos outros (Mendes et al., 2009); pois o índice $\mathrm{Z}$ não necessita de estimativas de covariâncias genéticas e fenotípicas e possibilita visualizar em quais caracteres o indivíduo ou a progênie têm fenótipos favoráveis e em quais ela é deficiente. Além disso, a identificação dos indivíduos de melhor desempenho é rápida e fácil. Entretanto, esse índice ainda não foi testado no melhoramento genético florestal.

A eficiência dos procedimentos empregados na seleção das melhores progênies também deve ser considerada. O método dos quadrados mínimos (MQM) tem sido utilizado na análise de experimentos dos programas de melhoramento genético de espécies anuais e perenes (Bison et al., 2004, 2006; Tolfo at al., 2005; Rocha et al., 2006a, 2006b; Botelho et al., 2007, 2011; Botrel et al., 2007, 2010; Silva et al., 2008; Bison et al., 2009; Mendes et al., 2009; Fonseca et al., 2010b). Entretanto, em experimentos desbalanceados, como é o caso dos experimentos com o gênero Eucalyptus, o procedimento de máxima verossimilhança restrita e melhor predição linear não viesada (restricted maximum likelihood/best linear unbiased prediction - REML/Blup) passou a ser mais indicado, em razão de sua eficiência ser igual ou superior à do MQM (Resende, 2007; Fonseca et al., 2010b). É importante ressaltar que os procedimentos MQM e o REML/Blup foram comparados quanto à estimação dos parâmetros genéticos (Rocha et al., 2006a, 2006b). Entretanto, o principal alvo dos programas de melhoramento, que são as melhores progênies selecionadas ou os ganhos obtidos por cada procedimento, não foram comparados.

O objetivo deste trabalho foi avaliar a eficiência do índice somatório das variáveis padronizadas - índice $\mathrm{Z}$ - na seleção de progênies de Eucalyptus por meio do MQM e Blup.

\section{Material e Métodos}

O teste de progênies utilizado no presente trabalho foi avaliado em dois ambientes da empresa Celulose Nipo-Brasileira S.A. (Cenibra), localizados no Município de Ipaba, MG. O ambiente 1 está situado a $19^{\circ} 32^{\prime} 03^{\prime \prime} \mathrm{S}$ e $42^{\circ} 29^{\prime} 29^{\prime \prime} \mathrm{W}$, com altitude de
$260 \mathrm{~m}$. A topografia desse ambiente é plana, em fundo de vale, e o solo é caracterizado como Neossolo Flúvico $\mathrm{Tb}$ distrófico. $\mathrm{O}$ ambiente 2 se situa a $19^{\circ} 31^{\prime} 21^{\prime \prime} \mathrm{S}$ e $42^{\circ} 29^{\prime} 38^{\prime \prime} \mathrm{W}$, e à altitude de $300 \mathrm{~m}$. Esse ambiente apresenta topografia inclinada, e o solo é caracterizado como Latossolo Amarelo distrófico. Ambos os ambientes têm precipitação média anual de $1.229,80 \mathrm{~mm}$ e umidade relativa de 70,5\%. A temperatura média anual é $20,5^{\circ} \mathrm{C}$, com máximas de $31^{\circ} \mathrm{C}$ e mínimas de $18,8^{\circ} \mathrm{C}$.

As progênies utilizadas foram obtidas por polinização controlada entre indivíduos de Eucalyptus grandis e Eucalyptus urophylla. Foram avaliadas 66 progênies comuns nos dois experimentos, implantados no ano de 2001, em delineamento experimental de blocos ao acaso, com cinco repetições, parcelas lineares de oito plantas e espaçamento de $3 \times 2 \mathrm{~m}$. Os manejos silviculturais utilizados foram os normalmente preconizados pela empresa em seus plantios comerciais.

No ano de 2004, com as plantas aos três anos de idade, foram obtidas estimativas de incremento médio anual de madeira (IMA) $\left(\mathrm{m}^{3} \mathrm{ha}^{-1}\right.$ por ano) a partir dos dados de cada indivíduo. Também foram realizadas mensurações das características tecnológicas da madeira: densidade básica da madeira (DB) $\left(\mathrm{kg} \mathrm{m}^{-3}\right)$; rendimento depurado de celulose $(\mathrm{RD})$ e álcali efetivo (AE), ambas em percentagem, por meio da espectroscopia do infravermelho próximo.

As análises estatísticas foram realizadas com os procedimentos MQM e REML/Blup. As análises de variância e as médias ajustadas foram obtidas no Proc GLM do SAS (SAS Institute, 2000), para cada ambiente, e na análise conjunta de ambientes, para cada característica considerada. As análises com o procedimento de modelos mistos REML/Blup foram obtidas por meio do programa Selegen (Resende, 2007). $\mathrm{Na}$ avaliação do teste de progênies por ambiente, foi utilizado o modelo estatístico $\mathrm{y}=\mathrm{Xr}+\mathrm{Zg}+\mathrm{Wp}+\varepsilon$, em que: y é o vetor de dados; $r$ é o vetor dos efeitos fixos de repetição, somados à média geral; $g$ é o vetor dos efeitos aleatórios genotípicos individuais $\mathrm{g} \sim \mathrm{N}$ $\left(0, \sigma_{\mathrm{g}}^{2}\right)$; $\mathrm{p}$ é o vetor dos efeitos aleatórios de parcela $\mathrm{p} \sim \mathrm{N}\left(0, \sigma_{\mathrm{p}}^{2}\right)$; e $\varepsilon$ é o vetor dos efeitos aleatórios dos erros $\varepsilon \sim \mathrm{N}\left(0, \sigma_{\varepsilon}^{2}\right)$. As letras maiúsculas representam as matrizes de incidência para os referidos efeitos. $\mathrm{Na}$ análise conjunta de ambientes, foi utilizado um modelo estatístico semelhante ao anterior, $\mathrm{y}=\mathrm{Xr}^{\prime}+\mathrm{Zg}+\mathrm{Wp}+\mathrm{Ti}+\varepsilon$, em que: $\mathrm{r}^{\prime}$ é o vetor dos 
efeitos fixos da combinação repetição-local, e i é o vetor dos efeitos aleatórios da interação genótipos $\mathrm{x}$ ambientes $\mathrm{i} \sim \mathrm{N}\left(0, \sigma_{\mathrm{i}}^{2}\right)$. As letras $\mathrm{X}$ e T representam as matrizes de incidência dos referidos efeitos.

Para estimar o grau de associação entre as características avaliadas, duas a duas, foram obtidas as correlações genéticas $\mathrm{r}_{\mathrm{G}_{\mathrm{xy}}}$ entre os desempenhos médios das progênies. Para tanto, foi utilizado o estimador de Bernardo (2002), dado por:

$$
\mathrm{r}_{\mathrm{G}_{\mathrm{xy}}}=\operatorname{COV}_{\mathrm{G}_{\mathrm{x} y}} / \sqrt{\sigma_{\mathrm{G}_{\mathrm{x}}}^{2} \sigma_{\mathrm{G}_{\mathrm{y}}}^{2}},
$$

em que: $\operatorname{COV}_{\mathrm{G}_{\mathrm{xy}}}$ é a covariância genética entre os desempenhos médios das progênies, para as características x e y; e $\sigma_{G_{x}}^{2}$ e $\sigma_{G_{y}}^{2}$ são as variâncias genéticas entre progênies, para as características $x$ ey, respectivamente. $\mathrm{Na}$ identificação das melhores progênies, com base nas quatro características simultaneamente, foram empregados dois índices de seleção: o índice clássico (Smith, 1936; Hazel, 1943) e o índice do somatório das variáveis padronizadas, índice Z (Mendes et al., 2009). O índice clássico considera as covariâncias genéticas e fenotípicas entre os n caracteres e, também, um peso econômico para cada caráter. $\mathrm{O}$ índice para cada progênie da população foi obtido pelo estimador $\mathrm{I}=\mathrm{b}_{1} \mathrm{x}_{1}+\mathrm{b}_{2} \mathrm{x}_{2}+\ldots+\mathrm{b}_{\mathrm{n}} \mathrm{x}_{\mathrm{n}}=\sum \mathrm{b}_{\mathrm{i}} \mathrm{x}_{\mathrm{i}}$, em que: I é o índice calculado para cada progênie da população; $b_{i}$ é o peso do caráter $\mathrm{i}$; e $\mathrm{x}_{\mathrm{i}}$ é o valor fenotípico para o caráter $\mathrm{i}$. Os valores de $b_{i}$ foram estimados por $b=\mathrm{P}^{-1} \mathrm{Ga}$, em que: $b$ é o vetor $n x 1$ dos valores de $b_{i}$; $\mathrm{P}^{-1}$ é a matriz nxn das covariâncias fenotípicas entre caracteres; $\mathrm{G}$ é a matriz nxn das covariâncias genéticas entre os caracteres; e a é o vetor $\mathrm{nx} 1$ dos pesos econômicos dos caracteres. No presente trabalho, foram utilizados pesos econômicos iguais a um, para cada um dos quatro caracteres. Para a obtenção deste índice, as análises foram realizadas com auxílio do programa Genes (Cruz, 2001).

No índice do somatório das variáveis padronizadas, os dados de caracteres de crescimento, IMA, e tecnológicos da madeira, $\mathrm{AE}, \mathrm{DB}$ e $\mathrm{RD}$, de todos os indivíduos do teste de progênies, foram padronizados, para torná-los diretamente comparáveis. Assim, a variável $Z_{\mathrm{ij}}$ foi obtida do estimador $\mathrm{Z}_{\mathrm{ij}}=\left(\mathrm{x}_{\mathrm{ij}}-\mathrm{m}_{\mathrm{j}}\right) / \mathrm{s}_{\mathrm{j}}$ (Ramalho et al., 2005), em que: $\mathrm{Z}_{\mathrm{ij}}$ é o valor da variável padronizada, correspondente ao indivíduo i na repetição $\mathrm{j}$; $\mathrm{x}_{\mathrm{ij}}$ é o valor observado da característica considerada do indivíduo i, na repetição $\mathrm{j} ; \mathrm{m}_{\mathrm{j}}$ é a média de todos os indivíduos na repetição j; e
$\mathrm{S}_{\mathrm{j}}$ é o desvio-padrão fenotípico da média na repetição j. Como a variável $\mathrm{Z}$ pode assumir tanto valores negativos como positivos, foi adicionado o valor três, de modo a tornar os valores positivos. Nesse caso, a média populacional, em vez de zero, assumiu o valor três.

O emprego desse índice na seleção simultânea dos quatro caracteres parte do pressuposto de que quanto maior o valor de $\mathrm{Z}$ melhor será a seleção. Contudo, quanto menor o valor da característica $\mathrm{AE}$, mais econômico será o processo de extração de celulose. Assim, para tornar os quatro caracteres atuantes na mesma direção, foi necessário fazer uma regra de três inversa com os valores de $\mathrm{AE}$, antes de sua padronização.

Após a padronização das variáveis, foi obtido o somatório de $\mathrm{Z}$ para cada indivíduo, que foi analisado por meio dos procedimentos MQM e Blup. Desse modo, foram obtidas as médias preditas das progênies para o índice $Z$, que foram ranqueadas em sentido favorável ao melhoramento tanto pelo MQM quanto pelo Blup. Foram realizadas comparações entre os índices $Z$, via MQM e Blup, e o índice clássico; posteriormente, foram obtidas as coincidências entre as sete melhores progênies identificadas por meio de cada índice.

As estimativas dos ganhos esperados com a seleção, para cada um dos quatro caracteres considerados, foram obtidas pela equação $\mathrm{GS}=\mathrm{dsh}_{\mathrm{mp}}^{2}$ (Falconer \& Mackay, 1996), em que: GS é o ganho esperado com a seleção, na média de progênies; ds é o diferencial de seleção, obtido pela diferença entre a média das sete melhores progênies selecionadas e a média das progênies da população original; e $\mathrm{h}_{\mathrm{mp}}^{2}$ é a estimativa da herdabilidade, na média de progênies.

O estimador utilizado para obter o ganho esperado com a seleção, em percentagem, foi GS $(\%)=\left(\mathrm{GS} / \mathrm{m}_{\mathrm{o}}\right) \times 100$, em que $m_{0}$ é a média das progênies da população original (Falconer \& Mackay, 1996). As estimativas dos ganhos esperados com a seleção e as das respostas correlacionadas à ela foram obtidas com auxílio do programa Genes (Cruz, 2001).

A magnitude da resposta correlacionada à seleção foi obtida pela expressão $\left(\mathrm{r}_{\mathrm{Gx}_{\mathrm{y}}} \mathrm{h}_{\mathrm{mp}_{\mathrm{x}}} / \mathrm{h}_{\mathrm{mp}_{\mathrm{y}}}\right) \times 100$, (Bernardo, 2002), em que: $r_{G_{x y}}$ é a estimativa da correlação genética do desempenho médio das progênies, para os caracteres x e y; $h_{m_{x}}$ é a raiz quadrada da herdabilidade média das progênies, para o caráter $\mathrm{x}$; e $\mathrm{h}_{\mathrm{mp}_{\mathrm{y}}}$ é a raiz 
quadrada da herdabilidade média das progênies para o caráter $\mathrm{y}$.

\section{Resultados e Discussão}

O material genético utilizado representa bem o germoplasma com que os melhoristas da região trabalham, para a produção de celulose. Assim, as estimativas obtidas refletem uma situação que pode ser generalizada no contexto do germoplasma utilizado.

Como as significâncias dos efeitos foram similares para todos os caracteres considerados, nas análises por ambiente e nas conjuntas via MQM e REML, optouse por apresentar somente as análises de deviance, estimadas por REML. Embora os dois ambientes de avaliação apresentem diferenças expressivas, com relação a relevo e tipo de solo, nas análises conjuntas para os quatro caracteres constatou-se que a interação progênies $\mathrm{x}$ ambientes foi significativa somente para AE e DB. Porém, mesmo para esses dois caracteres, as estimativas das correlações genéticas entre as médias dos desempenhos das progênies, nos dois ambientes, foram elevadas (Tabela 1). Esses resultados indicam que a interação observada foi predominantemente simples, ou seja, a classificação das progênies não sofreu alteração expressiva entre os ambientes avaliados (Vencovsky \& Barriga, 1992). Por essa razão, os resultados serão apresentados na média de ambientes. Efeitos significativos entre progênies foram observados nas análises para todas as características consideradas (Tabela 1). Assim, pode-se inferir que há variabilidade entre as progênies avaliadas e que há possibilidades de ganhos com a seleção para todas as características.

A estimativa da correlação genética entre os caracteres AE e RD foi alta e positiva (Tabela 2). Pode-se inferir que pelo menos uma parte dos genes envolvidos no controle dos caracteres $\mathrm{AE}$ e $\mathrm{RD}$ é a mesma, e que eles são pleiotrópicos ou ligados (Falconer \& Mackay, 1996). Esses genes estão atuando na mesma direção, o que é desejável de acordo com os melhoristas. Essa condição é muito favorável à seleção simultânea dos caracteres. As estimativas da correlação entre AE e DB, e também entre os caracteres $\mathrm{DB}$ e $\mathrm{RD}$, foram negativas. Nessas condições, os efeitos dos genes pleiotrópicos ou ligados, envolvidos no controle dos caracteres, atuam em direções opostas. As correlações com IMA foram todas positivas, e uma delas praticamente nula. Em princípio, esse resultado permite inferir que a seleção quanto ao volume de madeira, realizada no passado, não deve ter tido maior influência na expressão dos caracteres associados à qualidade da madeira.

Em progênies de meios-irmãos de E. camaldulensis, a estimativa da correlação entre os caracteres volume (V) e DB foi de 0,43 (Paula et al., 2002). Em avaliação de

Tabela 1. Análises de deviance quanto aos caracteres incremento médio anual de madeira (IMA) ( $\mathrm{m}^{3}$ ha ${ }^{-1}$ por ano), densidade básica (DB) $\left(\mathrm{kg} \mathrm{m}^{-3}\right)$, álcali efetivo (AE) (\%) e rendimento depurado de celulose (RD) (\%), obtidas na avaliação de progênies híbridas de irmãos completos de Eucalyptus grandis e E. urophylla, para cada ambiente e na análise conjunta de ambientes, em Ipaba, MG.

\begin{tabular}{|c|c|c|c|c|c|c|c|c|}
\hline \multirow[t]{2}{*}{ Efeito } & \multicolumn{2}{|c|}{ IMA } & \multicolumn{2}{|c|}{ DB } & \multicolumn{2}{|c|}{$\mathrm{AE}^{(2)}$} & \multicolumn{2}{|c|}{$\mathrm{RD}$} \\
\hline & Deviance & $\mathrm{LRT}^{(3)}$ & Deviance & LRT & Deviance & LRT & Deviance & LRT \\
\hline & \multicolumn{8}{|c|}{ Ambiente 1} \\
\hline Progênies ${ }^{(1)}$ & $17.540,39$ & $116,93 * *$ & $16.897,94$ & $122,11 * *$ & $9.998,63$ & $129,14 * *$ & $3.442,85$ & $91,79 * *$ \\
\hline Parcela $^{(1)}$ & $17.425,31$ & $1,85^{\mathrm{ns}}$ & $16.843,76$ & $67,93 * *$ & $9.899,88$ & $30,49 * *$ & $3.427,09$ & $76,03 * *$ \\
\hline \multirow[t]{2}{*}{ Modelo completo } & $17.423,46$ & - & $16.775,83$ & - & $9.869,49$ & - & $3.351,06$ & - \\
\hline & \multicolumn{8}{|c|}{ Ambiente 2} \\
\hline Progênies ${ }^{(1)}$ & $18.100,22$ & $150,53 * *$ & $17.822,58$ & $34,68 * *$ & $10.690,01$ & $190,11^{* *}$ & $3.856,59$ & $125,63 * *$ \\
\hline Parcela $^{(1)}$ & $17.949,81$ & $0,12^{\text {ns }}$ & $17.917,47$ & $129,57 * *$ & $10.510,02$ & $10,12 * *$ & $3.756,42$ & $25,46 * *$ \\
\hline \multirow[t]{2}{*}{ Modelo completo } & $17.949,69$ & - & $17.787,90$ & - & $10.499,90$ & - & $3.730,96$ & - \\
\hline & \multicolumn{8}{|c|}{ Análise conjunta de ambientes } \\
\hline Progênies ${ }^{(1)}$ & $35.377,15$ & $81,48 * *$ & $34.575,46$ & $22,57 * *$ & $20.373,93$ & $63,29 * *$ & $7.091,44$ & $59,12 * *$ \\
\hline Parcela $^{(1)}$ & $35.296,34$ & $0,67^{\mathrm{ns}}$ & $34.750,35$ & $197,46 * *$ & $20.349,04$ & $38,40 * *$ & $7.127,57$ & $95,25 * *$ \\
\hline Progênies x locais ${ }^{(1)}$ & $35.296,04$ & $0,37^{\mathrm{ns}}$ & $34.571,68$ & $18,79 * *$ & $20.323,01$ & $12,37 * *$ & $7.035,84$ & $3,52^{\text {ns }}$ \\
\hline Modelo completo & $35.295,67$ & - & $34.552,89$ & - & $20.310,64$ & - & $7.032,32$ & - \\
\hline Correlação $^{(4)}$ & \multicolumn{2}{|c|}{0,99} & \multicolumn{2}{|c|}{0,75} & \multicolumn{2}{|c|}{0,90} & \multicolumn{2}{|c|}{0,93} \\
\hline
\end{tabular}

${ }^{(1)}$ Deviance do modelo ajustado, sem os referidos efeitos. ${ }^{(2)}$ Valores invertidos. ${ }^{(3)}$ LRT, teste da razão da verossimilhança, com distribuição com 1 grau de

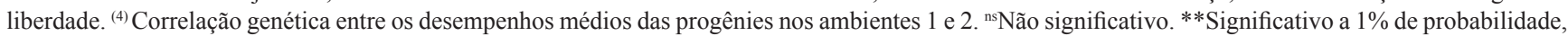
pelo teste de $\chi^{2}(1 \%=6,63 ; 5 \%=3,84)$. 
clones, Tolfo et al. (2005) também obtiveram estimativa positiva da correlação entre os caracteres $\mathrm{V}$ e $\mathrm{DB}(0,11)$. Assim, ao selecionar uma das características, haverá ganhos de seleção também para a outra. Em relação à correlação genética entre diâmetro à altura do peito (DAP) e DB, esses autores encontraram estimativas positivas, que variaram de 0,23 a 0,52 (Paula et al., 2002; Tolfo et al., 2005). No entanto, na avaliação de progênies híbridas de meios-irmãos de E. grandis x E. urophylla, Bison et al. (2006) obtiveram estimativas de correlações genéticas entre circunferência à altura do peito (CAP) e DB de $-0,57$ a $-0,39$, nos três locais avaliados. Estimativas de correlações entre os caracteres DAP e DB com magnitudes semelhantes às anteriores foram encontradas em progênies de meios-irmãos de E. globulus (Apiolaza et al., 2005) e E. nitens (Hamilton et al., 2009). Portanto, pode-se inferir que essas discrepâncias nas estimativas das correlações são esperadas, pois dependem da variação genética existente na população avaliada. Além disso, como os referidos caracteres são controlados por vários genes, as estimativas das correlações podem variar, a depender dos genes que estão segregando.

No melhoramento do Eucalyptus para produção de celulose e papel, a estimativa de correlação genética entre caracteres de crescimento e RD é de grande

Tabela 2. Estimativas das correlações genéticas entre os caracteres incremento médio anual de madeira (IMA) $\left(\mathrm{m}^{3} \mathrm{ha}^{-1}\right.$ por ano), álcali efetivo (AE) (\%), densidade básica (DB) $\left(\mathrm{kg} \mathrm{m}^{-3}\right)$ e rendimento depurado em celulose (RD) (\%), de progênies híbridas de irmãos completos de Eucalyptus grandis e E. urophylla.

\begin{tabular}{lcccc}
\hline Característica & IMA & AE & DB & RD \\
\hline IMA & 1,00 & 0,47 & 0,40 & 0,05 \\
AE & - & 1,00 & $-0,31$ & 0,72 \\
DB & - & - & 1,00 & $-0,40$ \\
RD & - & - & - & 1,00 \\
\hline
\end{tabular}

relevância, pois quanto maior o incremento de IMA e $\mathrm{RD}$, melhor o processo de polpação de celulose. Devese destacar que a madeira com elevado rendimento em polpa tem dois méritos industriais. Primeiro, passa a ser necessário adquirir, transportar e processar menor quantidade madeira, medida em metros cúbicos, para produzir a mesma quantidade de polpa, com óbvias reduções nos custos da matéria-prima. Em seguida, é consumida e, consequentemente, menor quantidade de reagentes por unidade de tempo tem que ser recuperada, o que leva a um aumento na capacidade de produção da fábrica (Borralho et al., 2007). Estimativas de correlação entre DAP e RD de 0,12 a 0,23 foram obtidas por Costa e Silva et al. (2009) e Hamilton et al. (2009). Assim, uma estimativa de correlação alta e positiva entre os caracteres de crescimento e $\mathrm{RD}$, apesar de ideal, não tem sido encontrada nos trabalhos realizados.

A seleção direta quanto a IMA proporcionou resposta correlacionada positiva nos outros três caracteres (Tabela 3). Contudo, a magnitude desta resposta variou de acordo com os caracteres analisados. A situação mais complexa ocorreu quando a seleção foi efetuada para os caracteres relacionados à qualidade da madeira como, por exemplo, a seleção em RD e resposta correlacionada para $\mathrm{DB}$, que vai em sentido contrário ao da seleção direta para DB.

Houve correspondência de $100 \%$ entre as sete melhores progênies identificadas pelos procedimentos MQM e Blup (Tabela 4). No presente trabalho, houve desbalanceamento nos dados uma vez que houve perda de $20 \%$ das árvores e assim, pode-se inferir que não houve vantagem no emprego do REML/Blup.

$\mathrm{Na}$ comparação entre os índices de seleção $\mathrm{Z}$ e clássico, verificou-se a coincidência de quatro progênies das sete selecionadas (Tabela 4). Em termos de ganho esperado com a seleção, o índice $Z$ apresentou estimativa semelhante ao clássico.

Tabela 3. Estimativas dos ganhos com a seleção direta (GS), e da herdabilidade na média de progênies ( $\mathrm{h}_{\mathrm{mp}}^{2}$ ), e magnitudes da resposta correlacionada com a seleção quanto aos caracteres: incremento médio anual de madeira (IMA) (em $\mathrm{m}^{3} \mathrm{ha}^{-1}$ por ano); álcali efetivo (AE) (\%); densidade básica (DB) $\left(\mathrm{kg} \mathrm{m}^{-3}\right)$; e rendimento depurado em celulose (RD) (\%), de progênies híbridas de irmãos completos de Eucalyptus grandis e E. urophylla.

\begin{tabular}{|c|c|c|c|c|c|c|}
\hline \multirow[t]{2}{*}{ Seleção efetuada no caráter (\%) } & \multicolumn{4}{|c|}{ Magnitude da resposta correlacionada à seleção } & \multirow[t]{2}{*}{ GS $(\%)$} & \multirow[t]{2}{*}{$\mathrm{h}_{\mathrm{mp}}^{2}$} \\
\hline & IMA & $\mathrm{AE}$ & DB & $\mathrm{RD}$ & & \\
\hline$\overline{\mathrm{IMA}}$ & 100,00 & 48,16 & 46,84 & 5,15 & 43,85 & 0,9127 \\
\hline $\mathrm{AE}$ & 45,86 & 100,00 & $-35,90$ & 72,65 & 8,66 & 0,8690 \\
\hline $\mathrm{DB}$ & 34,16 & $-27,50$ & 100,00 & $-35,23$ & 5,19 & 0,6656 \\
\hline RD & 4,85 & 71,75 & $-55,67$ & 100,00 & 2,04 & 0,8582 \\
\hline
\end{tabular}


$\mathrm{Na}$ Figura 1, estão apresentados os gráficos das progênies que apresentaram o melhor e o pior desempenho, na média dos dois ambientes avaliados

Tabela 4. Classificação das sete melhores progênies híbridas de irmãos completos de Eucalyptus grandis e E. urophylla, identificadas pelos índices clássico e $\mathrm{Z}$, pelos métodos dos quadrados mínimos (MQM) e melhor predição linear não viesada (Blup).

\begin{tabular}{lccc}
\hline Classificação & \multicolumn{2}{c}{ MQM } & Blup \\
\cline { 2 - 4 } & Clássico & Índice Z & Índice Z \\
\hline 1 & 58 & 58 & 58 \\
2 & 59 & 59 & 59 \\
3 & 64 & 21 & 21 \\
4 & 20 & 6 & 6 \\
5 & 7 & 42 & 42 \\
6 & 42 & 8 & 7 \\
7 & 43 & 7 & 8 \\
\hline Ganho de seleção (\%) & 43,60 & 46,68 & 48,07 \\
\hline
\end{tabular}

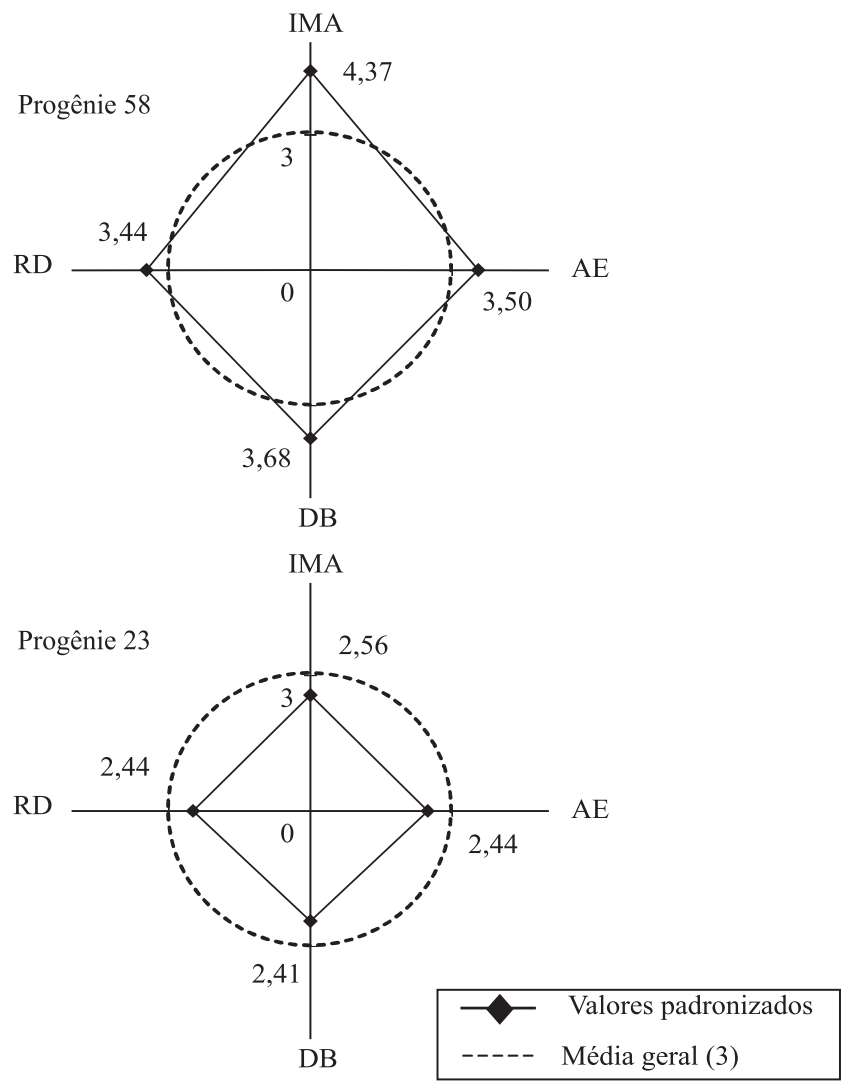

Figura 1. Representação gráfica dos valores padronizados dos caracteres incremento médio anual de madeira (IMA), álcali efetivo (AE), densidade básica (DB) e rendimento depurado em celulose (RD), das progênies híbridas de Eucalyptus grandis e E. urophylla, que apresentaram o maior (progênie 58) e o menor (progênie 23) valor de índice $\mathrm{Z}$ na média de ambientes. de acordo com o índice $Z$. Nota-se que a progênie 58 apresentou comportamento superior ao da média da população, nos quatro caracteres avaliados, e foi identificada como a de melhor desempenho. Esse resultado evidencia possibilidades de ganho com a seleção com essa progênie, ao passo que a progênie 23, com pior desempenho entre as 66 avaliadas, apresentou comportamento inferior à média da população nos quatro caracteres: IMA, AE, DB e RD.

Pode-se, portanto, inferir que o índice $\mathrm{Z}$ associa simplicidade à estimativa, pois não necessita de estimativas precisas de variâncias e covariâncias genéticas e fenotípicas e possibilita a obtenção de um gráfico, que permite a melhor visualização da contribuição de cada variável para a expressão do índice (Mendes et al., 2009). Além disso, podem ser utilizados diferentes pesos econômicos às variáveis utilizadas em seu cálculo, de acordo com o caso.

\section{Conclusões}

1. Os índices de seleção clássico e $Z$ coincidem na identificação das melhores progênies de Eucalyptus grandis e E. urophylla.

2. O índice $\mathrm{Z}$ possibilita verificar, graficamente, em quais caracteres as progênies híbridas de irmãos completos de E. grandis e E. urophylla apresentam alguma deficiência.

3. Não há diferença entre as melhores progênies híbridas de irmãos completos de E. grandis e E. urophylla, selecionadas pelo índice $\mathrm{Z}$ via MQM ou Blup.

\section{Agradecimentos}

Ao Conselho Nacional de Desenvolvimento Científico e Tecnológico por concessão de bolsa; e à Celulose Nipo-Brasileira S.A., pela concessão de dados utilizados neste trabalho.

\section{Referências}

APIOLAZA, L.A.; RAYMOND, C.A.; YEO, B.J. Genetic variation of physical and chemical wood properties of Eucalyptus globulus. Silvae Genetica, v.54, p.160-166, 2005.

BERNARDO, R. Breeding for quantitative traits in plants. Woodbury: Stemma, 2002. 368p.

BISON, O.; AGUIAR, A.M.; REZENDE, G.D.S.P.; RAMALHO, M.A.P. Inbreeding depression in Eucalyptus clones. Crop Breeding and Applied Biotechnology, v.4, p.459-464, 2004. 
BISON, O.; RAMALHO, M.A.P.; REZENDE, G.D.S.P.; AGUIAR, A.M.; RESENDE, M.D.V. de. Comparison between open progenies and hybrids performance in Eucalyptus grandis and Eucalyptus urophylla. Silvae Genetica, v.55, p.192-196, 2006.

BISON, O.; RAMALHO, M.A.P.; REZENDE, G.D.S.P.; AGUIAR, A.M.; RESENDE, M.D.V. de. Dialelo parcial entre clones de Eucalyptus camaldulensis e clones de E. urophylla, E. grandis e E. saligna. Revista Árvore, v.33, p.395-402, 2009.

BORRALHO,N.M.G.;ALMEIDA,H.;POTTS, B.M.Omelhoramento do eucalipto em Portugal. In: ALVES, A.M.; PEREIRA, J.S.; SILVA, J.M.N. (Ed.). O eucaliptal em Portugal: impactes ambientais e investigação científica. Lisboa: Instituto Superior de Agronomia, 2007. p.61-110.

BOTELHO, F.B.S.; RAMALHO, M.A.P.; ABREU, Â. de F.B. Seleção recorrente fenotípica para florescimento precoce de feijoeiro 'Carioca'. Pesquisa Agropecuária Brasileira, v.42, p.1437-1442, 2007.

BOTELHO, F.B.S.; RAMALHO, M.A.P.; ABREU, Â. de F.B.; ROSA, H.J.A. Multiline as a strategy to reduce damage caused by Colletotrichum. Journal of Phytopathology, v.159, p.175-180, 2011.

BOTREL, M.C.G.; SILVA, J.R.M. da; TRUGILHO, P.F.; ROSADO, S.C. da S.; FERNANDES, B.R. Ganho genético em propriedades físicas e mecânicas de clones de Eucalyptus. Scientia Forestalis, v.76, p.13-19, 2007.

BOTREL, M.C.G.; TRUGILHO, M.C.G.; ROSADO, S.C. da S.; SILVA, J.R.M. da. Seleção de clones de Eucalyptus para biomassa florestal e qualidade da madeira. Scientia Forestalis, v.38, p.237-245, 2010 .

COSTA E SILVA, J.; BORRALHO, N.M.G.; ARAÚJO, J.A.; VAILLANCOURT, R.E.; POTTS, B.M. Genetic parameters for growth, wood density and pulp yield in Eucalyptus globulus. Tree Genetics \& Genomes, v.5, p.291-305, 2009.

CRUZ, C.D. Programa GENES: versão Windows: aplicativo computacional em genética e estatística. Viçosa: UFV, 2001. 648p.

ELSTON, R.C. Weight-free index for the purpose of ranking or selection with respect to several traits at a time. Biometrics, v.19, p.85-97, 1963.

FALCONER, D.S.; MACKAY, T.F.C. Introduction to quantitative genetics. London: Longman Malaysia, 1996. 463p.

FONSECA, R.R.G.; GONÇALVES, F.M.A.; ROSSE, L.N.; RAMALHO, M.A.P.; BRUZI, A.T.; REIS, C.A.F. Realized heritability in the selection of Eucalyptus spp. trees through progeny test. Crop Breeding and Applied Biotechnology, v.10, p.160-165, 2010a.

FONSECA, S.M. da; RESENDE, M.D.V. de; ALFENAS, A.C.; GUIMARÃES, L.M. da S.; ASSIS, T.F. de; GRATTAPAGLIA, D. Manual prático de melhoramento genético do eucalipto. Viçosa: UFV, 2010b. 200p.

HAMILTON, M.G.; RAYMOND, C.A.; HARWOOD, C.E.; POTTS, B.M. Genetic variation in Eucalyptus nitens pulpwood and wood shrinkage traits. Tree Genetics and Genomes, v.5, p.307-316, 2009.
HAZEL, L.N. The genetic basis for constructing selections indexes. Genetics, v.28, p.476-490, 1943.

MARTINS, I.S.; CRUZ, C.D.; REGAZZI, A.J.; PIRES, I.E. Eficiência da seleção univariada direta e indireta e de índices de seleção em Eucalyptus grandis. Revista Árvore, v.27, p.327-333, 2003.

MARTINS, I.S.; MARTINS, R. de C.C.; PINHO, D. dos S. Alternativas de índices em uma população de Eucalyptus grandis Hill ex Maiden. Cerne, v.12, p.287-291, 2006.

MENDES, F.F.; RAMALHO, M.A.P.; ABREU, Â. de F.B. Índice de seleção para escolha de populações segregantes do feijoeiro-comum. Pesquisa Agropecuária Brasileira, v.44, p.1312-1318, 2009.

MULAMBA, N.N.; MOCK, J.J. Improvement of yield potential of the 'Eto Blanco' maize (Zea mays L.) population by breeding for plant traits. Egypt Journal of Genetics and Cytology, v.7, p.40-57, 1978.

PAULA, R.C. de; PIRES, I.E.; BORGES, R. de C.G; CRUZ, C.D. Predição de ganhos genéticos em melhoramento florestal. Pesquisa Agropecuária Brasileira, v.37, p.159-165, 2002.

PESEK, J.; BAKER, R.J. Desired improvement in relation to selection indices. Canadian Journal of Plant Science, v.49, p.803-804, 1969.

RAMALHO, M.A.P.; FERREIRA, D.F.; OLIVEIRA, A.C. de. Experimentação em genética e melhoramento de plantas. Lavras: UFLA, 2005. 326p.

RESENDE, M.D.V. de. SELEGEN-REML/BLUP: sistema estatístico e seleção genética computadorizada via modelos mistos. Colombo: Embrapa Florestas, 2007. 359p.

ROCHA, M. das G. de B.; PIRES, I.E.; ROCHA, R.B.; XAVIER, A.; CRUZ, C.D. Avaliação genética de progênies de meios-irmãos de Eucalyptus grandis por meio dos procedimentos REML/BLUP e da ANOVA. Scientia Florestalis, n.71, p.99-107, 2006 a.

ROCHA, M. das G. de B.; PIRES, I.E.; XAVIER, A.; CRUZ, C.D.; ROCHA, R.B. Avaliação genética de progênies de meios-irmãos de Eucalyptus urophylla utilizando os procedimentos REML/BLUP e E(QM). Ciência Florestal, n.16, p.369-379, 2006 b.

SAS INSTITUTE. SAS/STAT: user's guide. Version 8. Cary: SAS Institute, 2000.

SILVA, G.S. da; RAMALHO, M.A.P.; ABREU, Â. de F.B.; SILVA, F.B. Genetic control of early grain darkening of carioca common bean. Crop Breeding and Applied Biotechnology, v.8, p.299-304, 2008.

SMITH, H.F. A discriminant function for plant selection. Annals of Human Genetics, v.7, p.240-250, 1936.

TOLFO, A.L.T.; PAULA, R.C. de; BONINE, C.A.V.; BASSA, A.; VALLE, C.F. do. Parâmetros genéticos para caracteres de crescimento, de produção e tecnológicos da madeira em clones de Eucalyptus spp. Scientia Forestalis, n.67, p.101-110, 2005.

VENCOVSKY, R.; BARRIGA, P. Genética biométrica no fitomelhoramento. Ribeirão Preto: Sociedade Brasileira de Genética, 1992. 486p.

WILLIANS, J.S. The evaluation of a selection index. Biometrics, v.18, p.375-393, 1962.

$\overline{\text { Recebido em } 20 \text { de outubro de } 2010 \text { e aprovado em } 2 \text { de março de } 2011}$ 